\title{
Pajama Time: Working After Work in the Electronic Health Record
}

\author{
Harry S. Saag, MD ${ }^{1,2,3}$, Kanan Shah, BS ${ }^{2}$, Simon A. Jones, PhD 2,4 , Paul A. Testa, MD, JD 5 , \\ and Leora I. Horwitz, MD, MHS \\ 'Division of General Internal Medicine and Clinical Innovation, Department of Medicine, NYU School of Medicine, New York, NY, USA; ${ }^{2}$ Center for \\ Healthcare Innovation and Delivery Science, NYU Langone Health, New York, NY, USA; ${ }^{3}$ Roster Health, New York, NY, USA; ${ }^{4}$ Division of Healthcare \\ Delivery Science, Department of Population Health, NYU School of Medicine, New York, NY, USA; ${ }^{5}$ Department of Emergency Medicine, NYU \\ School of Medicine, New York, NY, USA.
}

J Gen Intern Med 34(9):1695-6 DOI: $10.1007 / \mathrm{s} 11606-019-05055-\mathrm{x}$

(c) Society of General Internal Medicine 2019

\section{INTRODUCTION}

Physician burnout is reaching pandemic levels, with highest incidence among primary care and emergency physicians. ${ }^{1}$ Both increased clinical effort and excess time using the electronic health record (EHR) are known contributors to physician burnout. ${ }^{2}$ We assessed whether clinical effort is associated with the amount of time ambulatory care physicians in an academic faculty group practice spend working after work in the EHR.

\section{METHODS}

We collected EHR usage data from the Epic (Madison, WI) user action logs, which track, among other things, physician minutes logged into the EHR at any time on days without scheduled appointments, as well as minutes logged into the EHR outside of $30 \mathrm{~min}$ before or after a provider's first and last scheduled appointment. We termed this time "work after work." Work after work data was collected for all ambulatory care physicians continuously practicing at any NYU Langone Health Faculty Group Practice site for 6 months between May 1 and October 31, 2018. We categorized physicians by the number of days with appointments per week, averaged over 6 months. Data were analyzed using SAS 9.4 (SAS Institute, Cary, NC). Least squares means of fixed effects were calculated, accounting for heterogeneous variances, and Tukey's multiple comparisons test was utilized to compare the means. This study met criteria for quality improvement work and was exempt from institutional review board review.

Prior Presentations None.

Published online May 9, 2019

\section{RESULTS}

We obtained data on 573 physicians. The majority of physicians were in a medicine $(52.4 \%)$ or surgery $(20.9 \%)$ specialty (Table 1). The average physician had scheduled appointments on 3 days/week, spent $83.3 \mathrm{~min}$ in the EHR on days without appointments, and spent $17.3 \mathrm{~min}$ in the EHR after work hours on days with appointments. However, time spent working on the EHR on days without appointments increased as the number of appointment days per week increased (15.9 min/unscheduled day for $\leq 1$ day/week vs. $170.4 \mathrm{~min} /$ unscheduled day [2.8 h] for $>4$ days/week, $p<0.001$ ), as did time spent on the EHR after hours on days with scheduled appointments (17.4 min/appointment-day for $\leq 1$ day/week vs. $22.0 \mathrm{~min} /$ appointment-day for $>4$ days/week, $p=0.03$ ) (Table 2).

\section{DISCUSSION}

We found that ambulatory physicians spend a substantial amount of time working in the EHR after hours and on unscheduled days (including weekends). While all physicians spent some portion of time working after work, physicians with more clinical time were disproportionately burdened by work after work. Those with the most clinical effort $(>4$ scheduled days/week) spent an average of $2.8 \mathrm{~h}$ on the EHR per unscheduled day. Importantly, from a burnout perspective, unscheduled days for this group of physicians are likely predominantly weekends and holidays. While we do not have burnout data to correlate with time spent working in the EHR, research has previously linked time spent in the EHR to burnout. $^{2-4}$

Table 1 Specialty of Study Physicians

\begin{tabular}{ll}
\hline \hline Specialty & $\boldsymbol{N ( \% )}$ \\
\hline Dermatology & $14(2.4)$ \\
Medicine & $300(52.4)$ \\
Mental health & $12(2.1)$ \\
Neurology & $41(7.2)$ \\
Obstetrics/gynecology & $17(3.0)$ \\
Pediatrics & $28(4.9)$ \\
Rehabilitation & $23(4.0)$ \\
Surgery & $120(20.9)$ \\
Other & $18(3.1)$ \\
\hline
\end{tabular}


Table 2 Time Spent on Work After Work, by Clinical Effort

\begin{tabular}{lll}
\hline $\begin{array}{l}\text { Days per week } \\
\text { with } \\
\text { appointments }\end{array}$ & $\begin{array}{l}\text { Average work after } \\
\text { work (min/day) on } \\
\text { days with } \\
\text { appointments }\end{array}$ & $\begin{array}{l}\text { Average work (min/ } \\
\text { day) on days without } \\
\text { appointments }\end{array}$ \\
\hline$(0-1](n=24)$ & $17.4 \pm 4.0$ & $15.9 \pm 2.4$ \\
$(1-2](n=61)$ & $12.9 \pm 2.2$ & $31.8 \pm 4.3$ \\
$(2-3](n=160)$ & $14.9 \pm 1.5$ & $49.2 \pm 3.7$ \\
$(3-4](n=190)$ & $17.2 \pm 1.5$ & $75.2 \pm 6.8$ \\
$(4-5](n=138)$ & $22.0 \pm 2.1$ & $170.4 \pm 30.8$ \\
& $p=0.03$ & $p<0.001$ \\
\hline
\end{tabular}

These findings contribute to our understanding of why physician burnout rates are increasing ${ }^{5}$ and add to existing concerns about EHR usability and documentation burden. Given that our results are consistent with an earlier study, ${ }^{6}$ our findings suggest a systemic national problem rather than a local institutional issue. It is likely that physicians cannot keep up with documentation requirements while seeing patients.

Our institution is now building dashboards to track work after work and piloting interventions to reduce physician work burden by offloading tasks to ancillary team members. Further, we are looking deeper into our Epic data to identify outliers who are struggling and offering personalized assistance to set up templates, quick actions, and workflow optimization, all of which can be studied to identify best practices. Work after work analyses could be employed at other institutions to motivate similar improvements.
Corresponding Author: Leora I. Horwitz, MD, MHS; Division of Healthcare Delivery Science, Department of Population Health NYU School of Medicine, New York, NY, USA (e-mail: leora. horwitz@nyulangone.org).

\section{Compliance with Ethical Standards:}

Conflict of Interest: The authors declare that they do not have a conflict of interest.

\section{REFERENCES}

1. Shanafelt TD, Boone S, Tan L, et al. Burnout and satisfaction with worklife balance among us physicians relative to the general us population. Arch Intern Med. 2012;172(18):1377-1385.

2. Gardner RL, Cooper E, Haskell J, et al. Physician stress and burnout: the impact of health information technology. J Am Med Inform Assoc. 2018.

3. Shanafelt TD, Dyrbye LN, Sinsky C, et al. Relationship Between Clerical Burden and Characteristics of the Electronic Environment With Physician Burnout and Professional Satisfaction. Mayo Clin Proc. 2016;91(7):836848.

4. Hauer A, Waukau HJ, Welch P. Physician Burnout in Wisconsin: An Alarming Trend Affecting Physician Wellness. WMJ. 2018;117(5): 194-200.

5. Rotenstein LS, Torre M, Ramos MA, et al. Prevalence of Burnout Among Physicians: A Systematic Review. JAMA. 2018;320(11):1131-1150.

6. Arndt BG, Beasley JW, Watkinson MD, et al. Tethered to the EHR: Primary Care Physician Workload Assessment Using EHR Event Log Data and Time-Motion Observations. Ann Fam Med. 2017;15(5):419-426.

Publisher's Note Springer Nature remains neutral with regard to jurisdictional claims in published maps and institutional affiliations. 